University of Nebraska - Lincoln

DigitalCommons@University of Nebraska - Lincoln

6-2007

\title{
Who shall lead? An integrative personality approach to the study of the antecedents of status in informal social organizations
}

\author{
Peter D. Harms \\ University of Nebraska - Lincoln, pharms@gmail.com \\ Brent W. Roberts \\ University of Illinois, Urbana-Champaign, bwrobrts@illinois.edu \\ Dustin Wood \\ University of Illinois, Urbana-Champaign
}

Follow this and additional works at: https://digitalcommons.unl.edu/managementfacpub

Part of the Management Sciences and Quantitative Methods Commons

Harms, Peter D.; Roberts, Brent W.; and Wood, Dustin, "Who shall lead? An integrative personality approach to the study of the antecedents of status in informal social organizations" (2007). Management Department Faculty Publications. 44.

https://digitalcommons.unl.edu/managementfacpub/44

This Article is brought to you for free and open access by the Management Department at DigitalCommons@University of Nebraska - Lincoln. It has been accepted for inclusion in Management Department Faculty Publications by an authorized administrator of DigitalCommons@University of Nebraska - Lincoln. 
Published in Journal of Research in Personality 41:3 (June 2007), pp. 689-699; doi: 10.1016/j.jrp.2006.08.001 Copyright @ 2006 Elsevier Inc. Used by permission.

http://www.elsevier.com/locate/jrp

Published online October 2, 2006.

\title{
Who shall lead? \\ An integrative personality approach to the study of the antecedents of status in informal social organizations
}

\author{
P. D. Harms, Brent W. Roberts, and Dustin Wood \\ Department of Psychology, University of Illinois, \\ 603 East Daniel Street, Urbana-Champaign, Illinois 61821, USA \\ Corresponding author - P. D. Harms
}

\begin{abstract}
The effects of personality traits, motives, and leadership identity claims on the attainment of status in informal, social organizations were assessed in several organizations using multiple indices of status. The power motive Hope for Power was predictive of holding executive offices. Extraversion and Conscientiousness predicted peer-ratings of social influence. Extraversion, Emotional Stability, and Dominance were related to subjective beliefs of personal power and influence. Seeing oneself as a leader mediated the effects of personality traits and motives on subjective sense of power and attaining social influence, but not achieving formal office. Together, these findings offer an integrated look at the unique relationships between personality and status attainment.
\end{abstract}

Keywords: status, power, leadership, personality

\section{Introduction}

Status has been referred to as "the single most important dimension in social interaction" (Ganzeboom \& Treiman, 1996, pg 203). Success or failure in this domain can impact personal well-being, health, opportunities for reproduction, and emotional experience (Anderson, et al., 2001; Keltner, et al., 2003). Power striving itself is seen as 
a fundamental contributor to eventual success in status attainment and has been considered by some researchers as a primary and universal human motive (Hogan \& Hogan, 1991). Despite elemental importance of status, the research on its antecedents has tended to be piecemeal possibly because psychologists tend to be both highly attuned to power relations and tend to have strong negative connotations of power itself (Winter, 1973). Relatively independent lines of research have focused on trait (Judge, et al., 1999), motive (Winter, 1973), or social cognitive antecedents (Chan \& Drasgow, 2001) to status attainment. To date, no research into the individual differences associated with status attainment has utilized a framework that combines the social cognitive, trait, and motive perspectives.

In the present paper, we test a model of personality, the neo-socioanalytic model (Roberts, 2006; Roberts and Wood, 2006) that integrates traditionally distinct domains in order to improve our ability to predict and understand status attainment. According to the neo-socioanalytic model, personality consists of the individual differences in traits, motives, role identities, abilities, and life stories that make each individual unique (Roberts and Wood, 2006; Roberts, et al., 2006). Furthermore, each of these domains represents a distinct psychological phenomenon, as opposed to personality models that prioritize one of the domains, such as traits, as causal above the others (e.g., McCrae \& Costa, 1999). Any comprehensive analysis of the role of personality in determining behavior should make use of these multiple approaches to studying personality if at all possible. Together, these elements of personality allow us to test the relationship between the core elements of personality and status attainment.

Moreover, the neo-socioanalytic model is explicitly hierarchical and integrative. For example, instead of conceptualizing traits and social cognitive approaches as competing systems, the neo-socioanalytic model proposes that social cognitive units of analysis are the lower-order mechanisms that underlie trait manifestations (Roberts \& Wood, 2006). Thus, the influence of traits and motives should be largely mediated by social cognitive factors, such as schemas and context derived knowledge and goals.

Since a comprehensive model of status attainment will necessarily include traits, motives, and social cognitive factors, it must then be asked which specific factors are the most relevant to success in this domain? The personality traits most associated with status attainment fall into the domain of agentic traits such as extraversion, dominance, and shyness (the lack thereof). Judge and colleagues (Judge, et al., 1999) conducted a meta-analysis linking status attainment, as represented by extrinsic career success with personality traits. They demonstrated that low Neuroticism, high Extraversion, low Agreeableness, and high Conscientiousness were all significant contributors to status when interpreted in this way. Another meta-analysis on leadership emergence (Judge, et al., 2002) revealed significant positive relationships with Extraversion, Conscientiousness, and Openness. Low Neuroticism was also correlated with leadership emergence. Other trait-oriented researchers have demonstrated that shyness, an orientation that causes individuals to withdraw from the world around them, is associated with lower occupational achievement (Caspi, et al., 1987). Individuality, a trait linked with striving to act in one's own interests rather than those of others, has been associated with greater status attainment in women (Helson \& Roberts, 1992). Both Social Potency and Achievement have been linked to holding leadership positions in a longitudinal study of twins (Arvey, et al., 2006). In student populations, Anderson, et al. (2001) showed that Extraversion was a significant predictor of status in a sorority, a fraternity, and a mixed dormitory. For 
men, Emotional Stability was also associated with achieving higher status. Additionally, Judge, et al. (2002) found that relationships between personality and leadership emergence in student populations were larger on average than in working populations. A common predictive factor in each of these studies is that successful individuals scored highly on agentic traits: Extraversion, Social Potency, Achievement, lack of shyness, and individuality. It has been argued that the link between agentic traits and status is caused by the approach-oriented behavior system associated with these traits (Keltner, et al., 2003). This approach-orientation in turn facilitates goal attainment across a wide variety of outcomes.

In the present study, we extend and improve upon the methods of previous research. First, rather than using only broad, trait-oriented measures of personality, we included measures of construct-targeted personality traits that had been linked to status attainment through prior research and theory, such as the trait of dominance (Hogan \& Kaiser, 2005). Extraversion can be thought of as consisting of two major subfacets, sociability and ambition/dominance, the latter of which has been linked to occupational advancement in previous research (Hogan, et al., 1998). Given the strong relationship found between status and agentic traits such as Extraversion in previous research, we thought it meaningful to separately analyze the effects of the status-relevant facet of that trait. Prior research as demonstrated that facet-level prediction of behavioral outcomes is better than broad-factor prediction (Paunonen \& Ashton, 2001).

Second, the exclusive use of trait measures in prior research may have resulted in the possible exclusion of important aspects of personality. Consistent with the multifaceted neo-socioanalytic model, we included measures of the motives Hope for Power and Fear of Power in the present study (Harms \& Roberts, 2006), which can be thought of as representing the approach and avoidance systems most related to hierarchy-striving in social systems. While traits represent the typical behavioral patterns of individuals, motives can be thought of as measuring the desires of the individuals, regardless of whether or not they are acted upon. In previous research, power motives have been linked to holding offices in student organizations (Winter, 1973) and with rapid promotions in corporations (McClelland \& Boyatzis, 1980).

Finally, to assess the social cognitive aspect of personality most linked to status attainment, we included a measure of Leadership Identity (Chan \& Drasgow, 2001) that has been linked to leadership potential. Previous research has shown that having a positive role identity for a specific domain facilitates performance and goal formation within that domain (Burke \& Hoelter, 1988). To this end, we assessed the degree to which individuals identified themselves as a leader in social groups.

Beyond using a more integrated personality model, we also assessed status in a more comprehensive manner than previous research. Information regarding the status of individuals was collected at several organizations using multiple criteria, such as formal (position-based), informal (peer-nominated), and subjective (self-rated) status. The use of multiple methods allowed us to avoid the inference that method variance accounts for part of the covariation between status and personality. We believe that these indices of status represent different, but unique approaches to the study of what it means to attain status.

The goal of this research is to show which personality variables are most relevant for status attainment in hierarchically organized, social groups. By using an integrative and comprehensive personality framework, we aim to lay out the process by which individual differences impact status attainment. Further, by differentiating be- 
tween different indices of status, we will demonstrate any unique relationships that may exist between specific aspects of personality and particular status outcomes.

\section{Method}

\subsection{Participants}

A total of 366 participants (203 women) were recruited from four fraternities and three sororities. Participants were given 10 dollars for completing the two-hour survey, and the organization was also compensated with money for their assistance with the study. The average age of the participants was 19.6 years old $(S D=1.1)$ and almost all were Caucasian.

\subsection{Materials and method}

2.2.1. Big five personality traits

A 53-adjective measure of the Big Five personality traits (Goldberg, 1993), first used by Walton and Roberts (2004), was employed in the assessment of general personality traits. Participants rated how much they agreed the adjectives were descriptive of them on a 5 point scale $(1=$ Strongly disagree, $5=$ Strongly agree $)$. $\alpha$ reliabilities ranged from .77 to .87 .

\subsubsection{Dominance}

A measure of trait dominance $(\alpha=.78)$ (Harms \& Roberts, 2006) making use of seven dominance-related adjectives (e.g., dominant, powerful, forceful) was embedded in the big five inventory and was rated using the same scale.

\subsubsection{Power motive}

Two 6-item self-report measures of power motivation were used to independently assess Hope for Power $(\alpha=.80)$ and Fear of Power $(\alpha=.79)$ (Harms \& Roberts, 2006). Participants rated items on a five-point scale according to how much they agreed with the description of their thoughts about power and status. An example item for Hope for Power is "I want to have power in every aspect of my life." An example item for Fear of Power is "The thought of being put in a position of authority scares me."

\subsubsection{Leadership identity}

A 6-item measure of leadership identity $(\alpha=.86)$ (Chan \& Drasgow, 2001) was used to assess self-reported shortened leadership identity. Examples of items include "I usually want to be a leader in the groups that I work in" and "I am definitely not a leader by nature" (reverse-scored). Participants rated the items using the same rating scale as they did for the power motives.

\subsubsection{Social influence}

Objective social influence was assessed by gathering peer ratings of how much influence each member of the organization possessed. Participants rated the extent to which each member "has influence among other people in the organization," with values ranging from 1 (weak) to 7 (strong). Given the large size of three of the organizations (membership rolls listed over 120 total members), for these organizations, the list of organization members was split into two, with participants having to rate only one half of the organization members or the other (randomly selected). Consequently, 
an average of 39 raters assessed each individual's social influence. For each person, ratings were averaged across all participants who had rated the person. The intraclass correlation (ICC; Shrout \& Fleiss, 1979) for ratings of social influence was positive for each of the organizations sampled, mean $\operatorname{ICC}(2,1)=.34$. Consequently, across organizations there was good reliability for ratings of influence ( $\alpha$ 's range from .90 to .98). Because this variable was substantially linked to seniority, the effect of tenure was removed by using the unstandardized residual of influence regressed on the number of years spent in the organization.

\subsubsection{Subjective influence}

A modified 5-item measure of Personal Sense of Power $(\alpha=.78)$ (Anderson, et al., 2006) was used to assess a participants' subjective belief in the degree to which they could influence decisions and activities within their fraternity. Examples of items include "My wishes don't carry much weight in this fraternity" and "I can get others in my fraternity to do what I want." Participants rated how much they agreed that the statement described them on a 5 point scale $(1=$ Strongly disagree, $5=$ Strongly agree $)$.

\subsubsection{Organization offices}

Members were asked to name the offices they held in the organization. Responses were categorized into executive offices ( 0 = held no executive office, $1=$ held an executive office), which was limited to executive board positions (e.g., president, vice-president, treasurer). Because only established members could hold offices, analyses were limited to members who had been in the organization one year or more. Within this sub-sample, $10 \%$ of the participating members held executive positions.

\section{Results}

\subsection{Relationships between personality and social status indices}

Table 1 presents the descriptive data from our sample as well as correlations between our predictor variables and the status indices. ${ }^{1}$ Because personality traits are best represented by a multivariate framework, we also entered the trait and motive predictors into a multiple regression predicting our status indices. The results of these regressions are presented in Table 2.

\subsection{Social influence}

Of the Big Five, Extraversion and Conscientiousness were significantly related to social influence. Leadership Identity showed the largest zero-order correlation while low Fear of Power and high trait Dominance were also correlated with social influence.

The regression analysis showed that Extraversion and Conscientiousness were independent predictors of social influence when controlling for all other predictors $\left(R^{2}=.09, F_{8,343}=4.31, p<.05\right)$.

\footnotetext{
${ }^{1}$ Gender played no significant role in shaping the pattern of relationships as none of the 50 possible gender*trait interactions predicting status outcomes reached statistical significance. Consequently, we analyzed the current sample across genders and organizations.
} 
Table 1. Descriptive statistics and correlations of predictors and criteria

\begin{tabular}{lccccccccccccc}
\hline & Mean & SD & 1 & 2 & 3 & 4 & 5 & 6 & 7 & 8 & 9 & 10 & 11 \\
\hline 1. Extraversion & 3.58 & .67 & .87 & & & & & & & & & & \\
2. Emotional stability & 2.91 & .52 & .04 & .80 & & & & & & & & \\
3. Agreeableness & 4.18 & .45 & $.23^{*}$ & $.13^{*}$ & .78 & & & & & & & \\
4. Conscientiousness & 3.71 & .61 & .08 & .08 & $.33^{*}$ & .82 & & & & & & \\
5. Intellect & 3.93 & .50 & $.40^{*}$ & .02 & $.33^{*}$ & $.14^{*}$ & .77 & & & & & \\
6. Dominance & 3.41 & .57 & $.48^{*}$ & .00 & -.02 & $.13^{*}$ & $.39^{*}$ & .78 & & & & & \\
7. Hope for Power & 2.30 & .67 & .09 & -.07 & $-.34^{*}-.13^{*}-.00$ & $.34^{*}$ & .80 & & & & \\
8. Fear of Power & 1.93 & .58 & $-.43^{*}-.15^{*}-.25^{*}-.29^{*}-.37^{*}-.35^{*}-.02$ & .79 & & & \\
9. Leadership Identity & 3.77 & .70 & $.47^{*}$ & .05 & $.21^{*}$ & $.24^{*}$ & $.39^{*}$ & $.47^{*}$ & $.23^{*}-.73^{*}$ & .86 & & \\
10. Social Influence & .00 & .93 & $.25^{*, \mathrm{~b}} .06$ & .05 & $.15^{*, \mathrm{~b}} .10$ & $.18^{*, \mathrm{~b}} .05$ & $-.22^{*, \mathrm{~b}} .26^{*}$ & - & \\
11. Subjective Influence & 3.48 & .62 & $.34^{*, \mathrm{~b}} .14^{*}$ & $.14^{*, \mathrm{~b}} .16^{*, \mathrm{~b}} .27^{*, \mathrm{~b}} .32^{*, \mathrm{~b}} .00-.32^{*}$ & $.30^{*}$ & $.42^{\mathrm{v}}$ & - \\
12. Executive Offices & .10 & .30 & .12 & -.03 & .10 & .06 & .12 & $.16^{*}$ & $.23^{*}-.19^{*}$ & $.24^{*}$ & $.39^{*}$ & $.27^{*}$ \\
\hline
\end{tabular}

$\alpha$ reliabilities are on the diagonal for self-report measures.

$n=323-363$

a $n=208$

b Sobel test revealed mediation by Leadership Identity.

${ }^{*} p<.05$

Table 2. Standardized betas of predictors with status criteria

\begin{tabular}{lcccc}
\hline & \multicolumn{2}{l}{ Informal power } & & Formal power \\
\cline { 2 - 3 } & Social influence $^{\mathrm{a}}$ & Subjective influence $^{\mathrm{a}}$ & & Executive office $^{\mathrm{b}}$ \\
\hline Extraversion & $.20^{*}$ & .15 & -.03 \\
Emotional stability & .04 & $.11^{*}$ & -.06 \\
Agreeableness & -.05 & .00 & $.20^{*}$ \\
Conscientiousness & $.12^{*}$ & .06 & -.03 \\
Intellect & -.03 & .08 & -.02 \\
Dominance & .02 & $.18^{*}$ & .05 \\
Hope for Power & .03 & -.06 & $.28^{*}$ \\
Fear of Power & -.11 & $-.14^{*}$ & -.16 \\
Overall $R^{2}$ & $.09^{*}$ & $.20^{*}$ & $.12^{*}$ \\
\hline
\end{tabular}

a $n=316-322$

$\mathrm{b}_{n}=189$

${ }^{*} p<.05$

\subsection{Subjective influence}

Each of the Big Five traits were significantly correlated with subjective influence. The correlations with these general variables ranged from a high of $r=.34$ for Extraversion to a low of $r=.14$ for Emotional Stability and Agreeableness. Leadership Identity, Fear of Power, and trait Dominance also correlated significantly with subjective influence.

Regression analyses showed that of the Big Five, Extraversion and Emotional Stability were the independent predictors of subjective influence. High trait Dominance and low Fear of Power also showed a significant relationship with subjective influence $\left(R^{2}=.20, F_{8,343}=10.33, p<.05\right)$. 


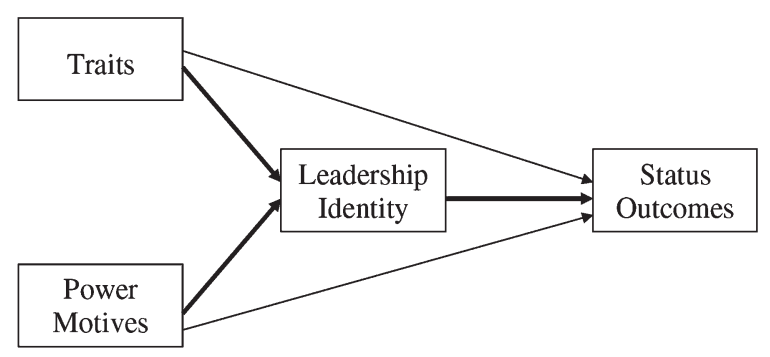

Figure 1. A neo-socioanalytic Model of Status Attainment.

\subsection{Executive offices}

None of the Big Five personality traits were significantly correlated with holding executive offices. All of the remaining variables showed significant correlations with holding an executive office. Leadership Identity correlated the most strongly with holding executive office, as well as Hope for Power, Fear of Power, and finally trait Dominance.

Regression analyses revealed that Hope for Power and Agreeableness proved to be a significant predictors of achieving executive office when controlling for all other predictors $\left(R^{2}=.05, F_{8,343}=2.41, p<.05\right) .^{2}$

\subsection{Mediation hypotheses}

We examined Leadership Identity as a mediator of the relationship between personality and status attainment using a procedure outlined by Baron and Kenny (1986). Our previous analyses demonstrated a relationship between personality traits and motives and our status outcomes. Further, when the significant correlates with status were tested for mediation with Sobel tests (Sobel, 1982), eight of fourteen personalitystatus relationships were significantly mediated by the Leadership Identity variable. See Table 1 for the results of these mediation analyses. Figure 1 illustrates the neo-socioanalytic model whereby personality traits and motives are mediated by Leadership Identity. Our prediction that Leadership Identity would mediate the influence of traits and motives on status attainment was supported in the cases of social influence and subjective influence, but not for attaining executive offices.

To illustrate the connection between traits (see Figure 2), motives and social cognitive factors, Dominance and Fear of Power were first entered into a regression equation predicting social influence $\left(F_{2,346}=10.62, p<.05\right)$. Fear of Power was significantly related to social influence while Dominance was only marginally related. Together, they explained $6 \%$ of the variance in the attainment of social influence. Next, Fear of Power and Dominance were entered into a regression equation predicting Leadership Identity $\left(F_{2,349}=238.72, p<.05\right)$. Both Fear of Power and Dominance proved to be significantly related to Leadership Identity and together explained $58 \%$ of the variance

\footnotetext{
${ }^{2}$ Interestingly, the relationship between Agreeableness and attaining office shows evidence of a suppressor effect as the zero-order correlation was insignificant. Post-hoc analyses revealed that Hope for Power was responsible for this suppression. A stepwise regression entering Agreeableness on the first step and Hope for Power on the second step showed the beta between Agreeableness and holding executive office increased from .10 to 21 .
} 

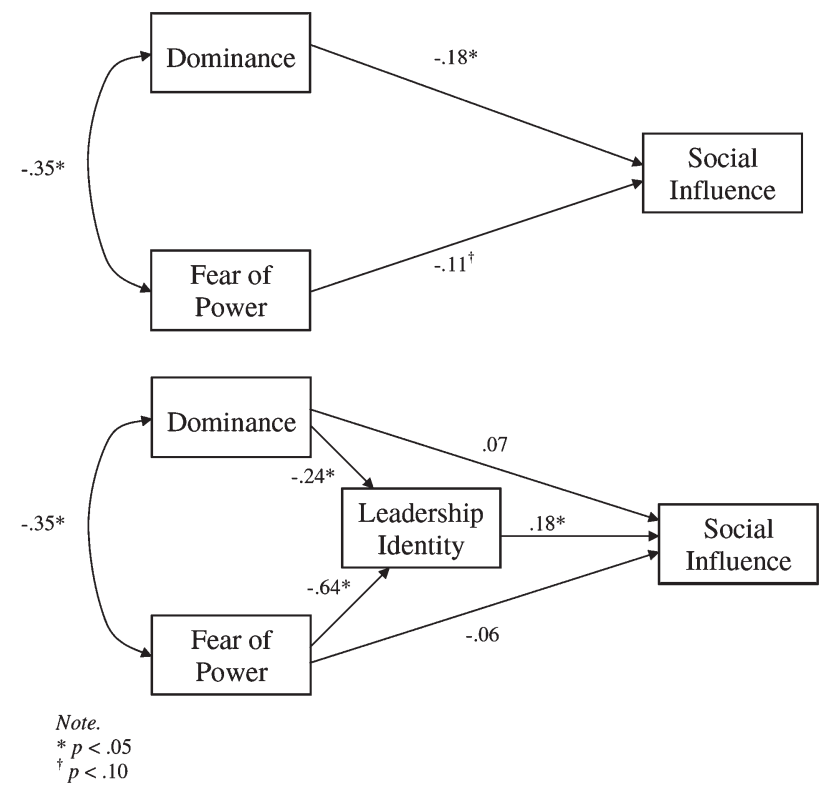

Figure 2. The mediation of traits and motives by identity constructs.

in Leadership Identity. Finally, Fear of Power, Dominance, and Leadership Identity were entered simultaneously into a regression equation predicting social influence $\left(F_{3,343}=8.89, p<.05\right)$. In this third equation, neither Dominance nor Fear of Power was significantly related to attaining social influence. However, Leadership Identity was significantly related. Together, these constructs accounted for $7 \%$ of the variance in attaining social influence. From these test we can see that for certain relationships, one's proximal identity significantly mediates the relationship between more distal motives and traits.

\section{Discussion}

In this study, we tested an integrative, hierarchical model of personality to better understand the role of individual differences on status attainment in hierarchical, social organizations. Using a multimethod approach, we attempted to replicate and improve on the findings of a set of previous studies investigating this phenomenon. To this end, we sampled numerous organizations consisting of all-male and all-female populations using a variety of personality assessment tools. We believe that this constitutes one of the most comprehensive attempts at investigating the role of individual differences in status attainment within the social organization context to date.

In our analysis, we attempted to distinguish between different methods of operationalizing status in an informal, yet hierarchical social group. We used a variety of methods to assess unofficial social influence, self-reported influence, and levels of office-holding in order to investigate the unique personological antecedents of each kind of status. By testing different methods of indexing status simultaneously, we hoped to distinguish between criteria effects and personological effects in a way that was not possible in previous research. 
Previous research indicated that a number of personality traits were related to status attainment. Agentic traits proved to be the most reliable predictors of status attainment due to their connection with goal attainment within the domain of social hierarchies. However, previous studies neglected to assess the breadth of personality constructs and rarely targeted their predictors to suit their criteria. By addressing these problems, the results of our current analyses revealed a more complicated story.

To some degree, the findings of prior researchers were replicated in our samples. For each status index used, an agentic trait or motive proved to be the best predictor of status attainment in our sample, although a number or other non-agentic traits also proved to be predictive of status. Social influence, being a status indicator closely linked with social reputation, was substantially linked with Extraversion and Conscientiousness. Presumably this is because Extraversion facilitates getting noticed and Conscientiousness enables individuals to present themselves as a role model. Subjective influence, on the other hand, is a status indicator linked with one's own self-appraisals. Consequently, it is no surprise that was linked to a variety of generally positive traits. Individuals who generally think highly of themselves are also individuals who believe themselves to have more power and more control over their lives and surroundings. Formal executive power, the most objective of the power indices, was most closely linked with having an ambitious power orientation. Thus, as predicted by previous research (Winter, 1973), it would seem that this motive orientation facilitates long-term goal acquisition in social domains organized by hierarchies. Also notable was that the attainment of prestigious offices in these democratic organizations was associated with high Agreeableness. Agreeableness provides the necessary social skills to offset the negative impressions peers often have of overtly ambitious individuals (Hogan \& Kaiser, 2005). Thus, in environments where leadership is consensual and chosen by the membership, we expect that both ambition and likeability are necessary for success in status attainment. However, it should be noted that another study using a somewhat different index of status failed to find a significant relationship between communal traits and formal status outcomes (Arvey, et al., 2006).

A primary contribution of this study was the assessment and utilization of a variety of trait, motive, and social cognitive constructs that are theoretically related to status attainment. The inclusion of these constructs allowed for a more comprehensive test of the relationship between personality and status as well as enabling a test of whether leadership identity mediated the relationship between core personality constructs and status attainment. Not only was it demonstrated that traits and motives independently contribute to the attainment of status, but that their effects are also largely mediated by one's own role-relevant identity. Interestingly, depending on how status was construed, different personality variables emerged as significant predictors of status attainment.

One of the limitations of the current study is the nature of the participants themselves. Our sample involved young people living together who came to power extremely quickly in democratic systems. While this provided an excellent context to study the nature of status attainment in an intimate environment, these results may not be reflective of status attainment in workplace settings where status is typically conferred by more senior members of the organization. Another limitation was that because the personality measures in question were all based on self-reports, it is possible that common-method variance may have played a role in the mediating relationships found in this study. 
Future research into the measurement of status needs to consider the multi-faceted nature of status by utilizing different methodologies that allow for a clearer understanding its antecedents. Future research into personality antecedents of status should take care to include relevant facets of those dimensions in order to maximize their ability to explain outcomes. Further, researchers should make efforts to get personality reports from knowledgeable others in order to prevent the potential problem of common-method variance between antecedents. Finally, longitudinal studies will be necessary to demonstrate not only which traits impact status attainment, but also how attaining status alters personality development. Longitudinal research will also be necessary to allow for better tests of the mediating relationship between social cognitive factors and other elements of personality.

\section{Conclusion}

The attainment of status in informal groups is not so different from that of other organizations. Just as occupational success and promotion have been shown to be related to conscientiousness, sociability, and ambition, so it is with our Greek organizations. In short, when members of a social organization are required to elect or nominate a leader from among themselves they tend choose someone well suited to the task.

\section{Acknowledgment}

Preparation of this paper was supported by a grant from the National Institute of Aging (AG19414).

\section{References}

Anderson, et al., $2001>$ C. Anderson, O. John, D. Keltner, and A. Kring, Who attains status? Effects of personality and physical attractiveness in groups, Journal of Personality and Social Psychology 81 (2001), pp. 116-132.

Anderson, et al., $2006 \rightarrow$ C. Anderson, O. John, and D. Keltner, The personal sense of power: Multi-level conceptualization and personality and antecedents. Submitted for publication (2006).

Arvey, et al., $2006 \triangleright$ R. Arvey, M. Rotundo, W. Johnson, Z. Zhang, and M. McGue, The determinants of leadership role occupancy: Genetic and personality factors, The Leadership Quarterly 17 (2006), pp. 1-20.

Baron \& Kenny, $1986 \rightarrow$ R. Baron and D. Kenny, The moderator-mediator variable distinction in social psychological research: Conceptual, strategic, and statistical considerations, Journal of Personality and Social Psychology 51 (1986), pp. 1173-1182.

Burke \& Hoelter, $1988>$ P. Burke and J. Hoelter, Identity and sex-race differences in educational and occupational aspirations formation, Social Science Research 17 (1988), pp. 29-47.

Caspi, et al., 1987 A. Caspi, G. Elder, and D. Bem, Moving away from the world: Lifecourse patterns of shy children, Developmental Psychology 24 (1987), pp. 824-831.

Chan \& Drasgow, $2001 \rightarrow K$. Chan and F. Drasgow, Toward a theory of individual differences and leadership: Understanding the motivation to lead, Journal of Applied Psychology 86 (2001), pp. 481-498.

Ganzeboom \& Treiman, 1996 H. Ganzeboom and D. Treiman, Internationally comparable measures of occupational status for the 1988 International Standard of Classification of Occupations, Social Science Research 25 (1996), pp. 201-239. 
Goldberg, 1993 L. Goldberg, The structure of phenotypic personality traits, American Psychologist 48 (1993), pp. 26-34.

Harms \& Roberts, $2006>$ P. D. Harms and B. W. Roberts, On the nature of power motivation. Manuscript in preparation (2006).

Helson \& Roberts, $1992 \rightarrow$ R. Helson and B. Roberts, The personality of young adult couples and wives' work patterns, Journal of Personality 60 (1992), pp. 575-597.

Hogan \& Hogan, $1991>$ R. Hogan and J. Hogan, Personality and status. In: D. G. Gilbert and J. J. Connolly, Editors, Personality, Social skills, and Psychopathology: An Individual Differences Approach, Plenum Press, New York (1991), pp. 137-154.

Hogan \& Kaiser, 2005 R. Hogan and R. Kaiser, What we know about leadership, Review of General Psychology 9 (2005), pp. 169-180.

Hogan, et al., 1998 J. Hogan, S. Rybicki, S. Motowidlo, and W. Borman, Relations between contextual performance, personality, and occupational advancement, Human Performance 11 (1998), pp. 189-207.

Judge, et al., $2002-$ T. Judge, J. Bono, R. Ilies, and M. Gerhardt, Personality and leadership: A qualitative and quantitative review, Journal of Applied Psychology 87 (2002), pp. 765-780.

Judge, et al., 1999 T. Judge, C. Higgins, C. Thoresen, and M. Barrick, The big five personality traits, general mental ability, and career success across the life span, Personnel Psychology 52 (1999), pp. 621-652.

Keltner, et al., 2003 D. Keltner, D. Gruenfeld, and C. Anderson, Power, approach, and inhibition, Psychological Review 110 (2003), pp. 265-284.

McClelland \& Boyatzis, 1980 D. McClelland and D. Boyatzis, The Leadership Motive Pattern and Long-Term Success in Management, McBer, Boston (1980).

McCrae \& Costa, 1999 R. McCrae and P. Costa, A five-factor theory of personality. In: L.A. Pervin and O.P. John, Editors, Handbook of personality: Theory and research (2nd ed.), Guilford Press, New York (1999), pp. 139-153.

Paunonen \& Ashton, 2001 S. Paunonen and M. Ashton, Big Five factors and facets and the prediction of behavior, Journal of Personality and Social Psychology 81 (2001), pp. 524-539.

Roberts, 2006 B. W. Roberts, Personality development and organizational behavior. In: B.M. Staw, Editor, Research on Organizational Behavior, . Elsevier Science/JAI Press (2006), pp. 1-41, Chapter 1.

Roberts, et al., 2006 B. W. Roberts, P. D. Harms, J. Smith, D. Wood, and M. Webb, Methods in personality psychology. In: M. Eid and E. Diener, Editors, Handbook of Psychological Assessment: A Multimethod Perspective, American Psychological Association, Washington, D.C. (2006), pp. 321-335, Chapter 22.

Roberts \& Wood, $2006>$ B. W. Roberts and D. Wood, Personality development in the context of the Neo-Socioanalytic Model of personality. In: D. Mroczek and T. Little, Editors, Handbook of Personality Development, Lawrance Erlbaum Associates, Mahwah, NJ (2006), pp. 11-39, Chapter 2.

Shrout \& Fleiss, 1979 P. Shrout and J. Fleiss, Intraclass correlations: Usas in assessing rater reliability, Psychological Bulletin86 (1979), pp. 420-428.

Sobel, $1982 \longrightarrow$ M. E. Sobel, Asymptotic intervals for indirect effects in structural equations models. In: S. Leinhart, Editor, Sociological Methodology 1982, Jossey-Bass, San Francisco (1982), pp. 290-312.

Walton and Roberts, $2004-$ K. Walton and B. Roberts, On the relationship between substance use and personality traits: Abstainers are not maladjusted, Journal of Research in Personality 38 (2004), pp. 515-535.

Winter, 1973 D. Winter, The Power Motive, The Free Press, New York (1973). 